\title{
Analysis of Turbulence Profiles from Three Tall Towers: Departure from Similarity Theory in Near-Neutral and Stable Conditions
}

\author{
Brent M. Bowen ${ }^{*}$ \\ Environmental Protection Department, Lawrence Livermore National Laboratory, Livermore, California, USA
}

\begin{abstract}
Long-term wind and turbulence profiles were analyzed for all stability conditions at three tall, multi-level towers located at the Los Alamos National Laboratory (LANL), Rocky Flats Environmental Plant (RF), and the Boulder Atmospheric Observatory (BAO). The LANL and RF sites are located in complex terrain and the BAO is located over relatively simple terrain, but within 3 to $5 \mathrm{~km}$ of an abrupt 20 to $30 \mathrm{~m}$ increase in terrain. Results indicate that normalized turbulence parameter profiles at all three sites agree well with widely used empirical relationships during unstable conditions.

During near neutral conditions, $\sigma_{u}$ parameter profiles are also well behaved at all three sites while $\sigma_{w}$ increases with height for complex fetch (BAO downwind of bluff, LANL, and RF) while $\sigma_{w}$ remains nearly constant up to $200 \mathrm{~m}$ AGL at BAO with simple fetch. The $\sigma_{w} / u *$ values at $10-\mathrm{m}$ AGL are close to one at all sites and they increase by an order of $50 \%$ in the lowest 60 to $200 \mathrm{~m}$ for complex fetch and remain approximately constant in the lowest $200 \mathrm{~m}$ with simple fetch.

During very stable conditions, typical values of $\sigma_{u}$ and $\sigma_{v}$ range between 0.4 to $0.6 \mathrm{~ms}^{-1}$ and increase slightly with height while median $\sigma_{w}$ values nearly double from about 0.1 to $0.2 \mathrm{~ms}^{-1}$ between the 10 - and 100 to $200-\mathrm{m}$ levels. A comparison of predicted with measured $u *$ values at two of the sites shows generally good agreement over 6 stability categories. It is suggested that M-O similarity theory will usually greatly underestimate vertical diffusivity and dispersion during very stable conditions, especially at larger heights, based on idealized Kz profiles calculated from measured $\sigma_{w}$ values. Finally, rules of thumb are formulated to describe departure from similarity theory during near-neutral and stable conditions.
\end{abstract}

Keywords: Turbulence, towers, similarity.

\section{INTRODUCTION}

Atmospheric dispersion models require accurate turbulence estimates in order to reliably characterize downwind dispersion and atmospheric pollutant concentrations. While simple Gaussian dispersion models often use PasquillGifford-Turner dispersion coefficients to estimate downwind dispersion, the use of Monin-Obhukov similarity theory with near surface wind speed $(u)$, estimated roughness length $\left(z_{o}\right)$, mixing layer height $(h)$, and experimentally derived factors can reliably characterize three-dimensional downwind dispersion over various kinds of terrain. Even when turbulence parameters are measured at standard tower height $(\sim 10 \mathrm{~m})$, the turbulence parameter profile must be estimated throughout the surface layer using, for example, the power law recommended by the U.S. Environmental Protection Agency [1].

The use of widely used turbulence relationships is often inappropriate since they are based on a limited number of field experiments, conducted primarily over flat, smooth, and uniform (FSU) terrain. Hicks [2] points out: "The extensive

*Address correspondence to this author at the Environmental Protection Department, Lawrence Livermore National Laboratory, Livermore, California, USA; E-mail: bbowen@yahoo.com field studies of the 1960s and 1970s should offer no great solace, since the sites were carefully chosen as outdoor laboratories to test similarity and its consequences in fitting circumstances. There was no test of similarity in conditions that violated the assumptions of similarity."

Several later field studies provided insight on the effect of complex terrain on downwind turbulence and dispersion. Panofsky et al. [3] first suggested that rolling terrain enhanced the wind direction standard deviation, $\sigma_{\theta}$. Their findings indicate that $\sigma_{\theta}$ typically increases by $150 \%$ to the lee of a low mountain and by $40 \%$ in slightly rolling terrain compared to flat terrain. Hanna [4] demonstrates in another field study that $\sigma_{\theta}$ is typically $60 \%$ larger in a river valley for cross-valley flow, likely a result of upwind terrain irregularities. The same study also suggests that irregular terrain causes the horizontal dispersion parameter, $\sigma_{y}$, to increase by an even greater amount. Ludwig and Dabberdt [5] show that $\sigma_{\theta}$ increases by $10 \%$ to $85 \%$ downwind of downtown St. Louis versus more rural upwind fetch. Tieleman [6] points out that peak wavelengths of horizontal turbulence components caused by complex terrain can require several kilometers of fetch to dissipate and adjust to the 'local' terrain. However, this study as well as those by Panofsky et al. [3] and other applied researchers have generally dismissed 
the effect of terrain features on vertical turbulence and assume that the higher frequency vertical turbulence quickly adjusts to local terrain.

The neglect of terrain-enhanced vertical turbulence may actually have occurred because many field experiments have taken place in homogenous terrain and $\sigma_{w}$ profiles have typically been limited to about $25 \mathrm{~m}$ AGL or less [7]. Beljaars et al. [8] demonstrate in a flat agricultural area $(\mathrm{Ca}-$ bauw tower) that measured $\sigma_{w}$ and friction velocity $(u *)$ both increase $40 \%$ with increasing height above ground from 3.5 to $22.5 \mathrm{~m}$ with non-uniform fetch and they remain unchanged with uniform fetch. Later studies by Bowen $[9,10]$ indicate that during near-neutral conditions with wind speed (u) of 5 to $6 \mathrm{~ms}^{-1}, \sigma_{w}$ increases by about $0.3 \mathrm{~ms}^{-1}$ in the lowest 100 meters at the three sites investigated in this study: a 'locally' smooth site surrounded by rolling terrain, a forested site with canyons, and at a site $4 \mathrm{~km}$ downwind of a 20 - to $30-\mathrm{m}$ high bluff. All of these studies indicate that while $\sigma_{w}$ increases with height, the standard deviations of longitudinal $\left(\sigma_{u}\right)$ and lateral $\left(\sigma_{v}\right)$ wind speed are nearly constant with height in heterogeneous terrain. Terrain has increasingly less influence on turbulence, as conditions become more unstable.

The stable boundary layer (SBL) presents challenges to estimate turbulence in all terrain. Hanna and Chang [11] point out that horizontal meandering motions near the surface are always present during stable conditions at all types of field sites and they therefore recommend a minimum $\sigma_{v}$ value of $0.5 \mathrm{~ms}^{-1}$ over one-hour averaging times. Enhanced vertical turbulence in the SBL is less understood yet potentially more important in downwind dispersion. Field studies at Savannah River Laboratory [12] and Rocky Flats [13] demonstrate how the combination of strong wind direction shear and enhanced vertical turbulence in the lowest hundreds of meters can influence vertical and horizontal transport of surface tracer material. This results in broader plumes and secondary plumes inconsistent with near-surface wind direction. The formation of a nocturnal, low-level jet is suggested to enhance $\sigma_{w}$ in the 100-500 m AGL level (and causes larger ground-level pollutant concentrations from medium and tall stacks), especially after 10:00 p.m. LT according to Hanna and Chang [11]. These studies and others suggest that enhanced $\sigma_{w}$ in the SBL can lead to much stronger vertical diffusivity than indicated by M-O similarity theory and yield plume transport errors during times with strong horizontal wind direction shear.
Long-term wind and turbulence profiles up to $200 \mathrm{~m}$ AGL and $u_{*}$ are analyzed in this study for all stability conditions at three tall, multi-level towers located in the western U.S. The Los Alamos National Laboratory (LANL) and Rocky Flats Environmental Technology (RF) sites are located in complex terrain and the Boulder Atmospheric Observatory $(\mathrm{BAO})$ is located over relatively simple terrain, but within 3 to $5 \mathrm{~km}$ of an abrupt 20 to $30 \mathrm{~m}$ increase in terrain. Profiles of median, 15-minute averaged turbulence parameters $\left(\sigma_{u}, \sigma_{v}\right.$, and $\left.\sigma_{w}\right)$, standard deviations of horizontal and vertical wind angle fluctuations $\left(\sigma_{\theta}\right.$ and $\left.\sigma_{\phi}\right)$, and winds are analyzed for eight wind direction sectors at the three towers. Predicted $u *$ at BAO and LANL are compared to measured values at both sites. Finally, differences between widely used $K z$ profiles based on similarity theory and profiles estimated using measured $\sigma_{w}$ during stable conditions, and their possible effect on model results, are discussed.

\section{DESCRIPTION OF SITES AND INSTRUMENTA- TION}

The three tower sites used in this study are located over various types of terrain with semiarid climate (see Table 1). The RF and BAO sites are located east of the Front Range in east-central Colorado and LANL is located in north-central New Mexico. The site elevations range from 1575 MSL at BAO to $2250 \mathrm{MSL}$ at LANL. The fetch is complex at RF and LANL with sharp terrain changes of up to 50 and $100 \mathrm{~m}$ caused by drainage areas and canyons, respectively [9]. The vegetation is sparse at RF while ponderosa trees are widespread at LANL. The local terrain at BAO is simple, located in slightly rolling farmland with ground cover of wheat or wheat stubble with 0.25 to $0.5 \mathrm{~m}$ height [14]. The low relief, with slopes of $20 \mathrm{~m} \mathrm{~km}^{-1}$ or less, extends at least $10 \mathrm{~km}$ to the north, east, and south of this site. However, a 20 to $30-\mathrm{m}$ bluff extends approximately $3.5 \mathrm{~km}$ to the west and 4 to $5 \mathrm{~km}$ to the northwest and southwest of the tower.

All towers are guyed with open lattice structures of galvanized steel. Booms are used to support the tower instruments. While towers at RF and LANL are instrumented to take routine operational measurements, the $\mathrm{BAO}$ was equipped with various sensors from late March through early June of 1995 as part of the Ground-Based Remote Sensor Characterization study [15]. Note that the data measured at the $300-\mathrm{m}$ level were affected by electrical interference and therefore were not analyzed in this study.

Wind direction and speed were measured by lowthreshold cup and vane systems at RF and by low threshold propeller anemometers at LANL. Propellers with an extender

Table 1. Site Characteristics of the Three Towers Used in this Study

\begin{tabular}{|c|c|c|c|c|c|}
\hline Site & Period of Record & $z_{o}(\mathbf{c m})$ & Tower Heights $(\mathbf{m})$ & Fetch & Comments \\
\hline \hline RF & 1 year & $2.5-8$ & $10,25,60$ & Rolling terrain with $.5 \mathrm{~m}$-high grass & Site on $2.0^{\circ}$ sloping bench \\
\hline LANL & 1 year & $40-90$ & $12,23,46,92$ & $\begin{array}{c}\text { Canyons } 50-100 \mathrm{~m} \text { deep and } 100-200 \mathrm{~m} \\
\text { wide; } 20 \text {-m-high ponderosa pines }\end{array}$ & Site on $2.5^{\circ}$ sloping plateau \\
\hline BAO & 10 weeks & $0.6-34$ & $10,50,100,200$ & $\begin{array}{c}\text { Gently rolling with } .25-.5 \mathrm{~m} \text { wheat/wheat } \\
\text { stubble }\end{array}$ & $\begin{array}{c}20-30 \mathrm{~m} \text { bluff located } 3.5-5 \\
\mathrm{~km} \text { toward SW-NW }\end{array}$ \\
\hline
\end{tabular}


and medium weight blades measured vertical velocity at both of these sites. Sonic anemometers provided the wind direction and speed and vertical velocity at BAO. Thermistors located at multiple levels provided temperature data at all sites. The data were sampled at a $1 \mathrm{~Hz}$ rate at RF and LANL and a $10 \mathrm{~Hz}$ rate at $\mathrm{BAO}$. Dataloggers at all towers provided 15-minute averages. Momentum flux, based on eddy correlation of measured horizontal and vertical wind fluctuations, was used to calculate $u_{*}$ at LANL and BAO.

\section{DATA ANALYSIS DESCRIPTION}

Fifteen-minute averaged wind, turbulence, and momentum flux data were analyzed for eight directional sectors $\left(45^{\circ}\right.$ wide) and 6 stability categories, defined by 6 ranges of Richardson number (Ri) values. The 15 -minute averaging period is a good compromise since a shorter period may be inadequate to characterize turbulence while wind direction changes or "meandering" will become more important for longer averaging periods such as an hour, especially during stable conditions. These ranges correspond roughly to Pasquill stability categories defined according to a method suggested by Sedefian and Bennett [16] based on the Businger [17] formulation. The Ri values, detailed in section 4, are calculated using 15-minute averages of $u$ and potential temperature $(\theta)$ values at the two lowest heights of the towers for each site and sector:

$R i=g / T(\Delta \theta / \Delta z) /(\Delta u / \Delta z)^{2}$,

where $g$ is the acceleration of gravity and $\mathrm{T}$ is the average temperature. Note that the bottom and top of the layers (i.e., the two lowest measurement levels) used to calculate Ri are $10-25,11-23$, and $10-50 \mathrm{~m}$ at the RF, LANL, and BAO towers, respectively.

The $z_{o}$ value was calculated from measured $\sigma_{u}$ and $u$ at 10 - to 12 -m heights for each site sector during more strictlydefined near-neutral stability by the following expression suggested by Tieleman [6] and others:

$$
z_{o}=\exp \left[\ln z-1 /\left(\sigma_{u} / u\right)\right]
$$

Nighttime cases with 10 - to $12-\mathrm{m} u$ greater than $5 \mathrm{~ms}^{-1}$ and daytime cases with $u$ greater than $5 \mathrm{~ms}^{-1}$ with slight insolation and with $u$ greater than $6 \mathrm{~ms}^{-1}$ with moderate insolation are defined as near neutral. Slight and moderate insolation ranges are defined as $70-350$ and $350-700 \mathrm{Wm}^{2}$, respectively, and a value of $70 \mathrm{Wm}^{2}$ is used to define day and night. Equation (2) is derived from the logarithmic wind profile equation and the widely used approximation $\sigma_{u} / u_{*}=2.5$ based on measurements over flat and smooth terrain.

The $u *$ values are estimated at all sites using the following relationship suggested by Holtslag and Van Ulden [18] based on integrated flux-profile relationships of Dyer and Hicks $[19,20]$ :

$u_{*}=k U_{z}\left[\ln \left(z / z_{o}\right)-\psi_{M}(z / L)+\psi_{M}\left(z_{o} / L\right)\right]^{-1}$, where $\mathrm{k}$ is the von Karman constant $(0.41), U_{z}$ is the wind speed $\left(\mathrm{ms}^{-1}\right)$ at a specific height, $\mathrm{L}$ is the Monin-Obukhov length (m) and $\psi_{M}$ is a function of the dimensionless wind gradient, $\phi_{\mathrm{m}}$.

The $\mathrm{L}$ is estimated from the calculated Ri using the following relationships:

$$
\begin{aligned}
& \mathrm{z} / \mathrm{L}=\mathrm{Ri} \text { for } \mathrm{Ri}<0 \\
& \mathrm{z} / \mathrm{L}=\mathrm{Ri} /(1-5 \mathrm{Ri}), \text { for } 0 \leq \mathrm{Ri}<0.2
\end{aligned}
$$

Arya [21] points out that the second relationship of Eq. (4) implies a critical value of $\mathrm{Ri} \approx 0.2$, although similarity theory is not expected to remain valid in extremely stable conditions. Therefore, a maximum $\mathrm{L}$ value of 12 (RF and BAO) and 17 (LANL) is assumed based on relationships suggested by Golder [22]. The $u *$ was calculated from winds at $10-\mathrm{m}$ heights at BAO and RF and the $12-\mathrm{m}$ height at LANL. Note that $z_{o}$ is calculated using $\sigma_{u}$ in Equation (2) with the $u *$ representing a regional value affected by more distant upwind terrain instead of a local value where $z_{o}$ is calculated from wind speed profiles. Verkaik and Holstag [23] point out that meteorological masts are often placed in sites with undisturbed terrain and therefore local roughness is usually smaller than the large-scale roughness.

Several empirical studies at tall towers indicate that surface layer theory is typically valid up to heights of $80-\mathrm{m}$ in all stabilities [24] and at least $150 \mathrm{~m}$ during windy, nearneutral conditions [25] at sites with homogeneous and relatively flat terrain. Gryning et al. [24] also point out that departure from surface layer theory gradually increases above the surface layer up to a $300-\mathrm{m}$ height. Therefore measurements from most if not all tower levels in this study are expected to be within or slightly outside the surface layer in unstable and near-neutral conditions. However, some or all tower levels are probably above the surface layer and occasionally above the boundary layer during stable conditions.

Median wind speeds, turbulence parameters, and $u *$ were calculated in this study. Median values are better able to describe 'typical' conditions than mean values since they give less weight to extreme data (e.g., very strong winds).

\section{RESULTS AND DISCUSSION}

\subsection{Ri-Based Stability Category Distribution At Tower Sites}

The distribution of stability categories based on Ri range was calculated for 4 fetches and is shown in Fig. (1). Typical Ri values of the class limits are also shown. Note that both $\mathrm{BAO}$ fetches experience somewhat more neutral and nearneutral conditions than the LANL and RF towers during the respective study periods. Some of the differences are probably attributed to the limited study period at BAO (i.e., during relatively breezy spring). The greater frequency of unstable conditions for simple compared to complex fetch at BAO results from diurnal wind direction change. Finally, persistent nocturnal drainage winds contribute to the very high frequency of F stability at both LANL and RF. 


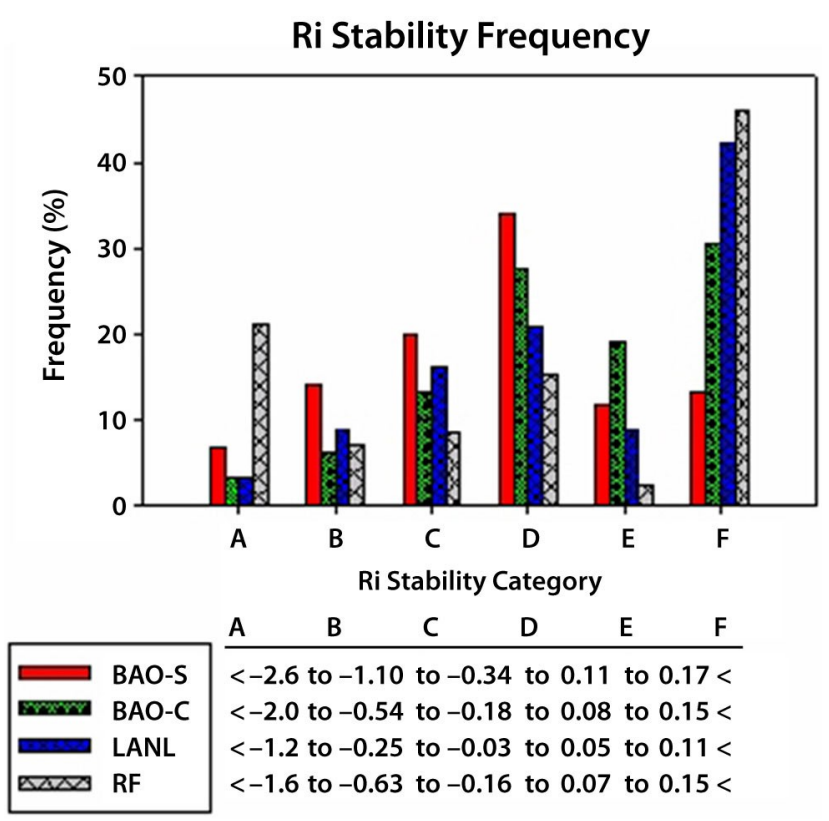

Fig. (1). Frequency distribution of stability categories based on Ri for 4 fetches at 3 sites. Class limits for each stability category transition are shown for each fetch. The simple and complex fetches at $\mathrm{BAO}$ are denoted as $-\mathrm{S}$ and $-\mathrm{C}$, respectively.

\subsection{Normalized Turbulence Parameter Profiles by Sta- bility}

Profiles of normalized turbulence parameters were calculated for all Ri classes and are shown in Figs. (2-7). Although turbulence parameter values varied across individual directional sectors, the normalized values were more constant and therefore averaged across sectors. Note that $\sigma_{w}$ is more appropriately scaled by $w_{*}$ for the most unstable conditions and larger heights; however, $u_{*}$ values were used throughout for ease of comparisons and because the boundary layer depths were unavailable in order to calculate $w_{*}$. The $\sigma_{u} / u_{*}$ values for A are at or somewhat below an expected range of 3.3 to 4.8 based on equations suggested by Panofsky et al. [26] using ranges of $\mathrm{h}$ and $\mathrm{L}$ between 1 and 2 $\mathrm{km}$ and 10 to $20 \mathrm{~m}$, respectively. The $\sigma_{v} / u_{*}$ values are somewhat larger than $\sigma_{u} / u_{*}$ values and are within the previously mentioned expected range, although they decrease with height. The $\sigma_{w} / u_{*}$ values increase sharply with height as expected for all fetches at approximately the same rate. The $\sigma_{w} / u_{*}$ values at BAO and LANL agree reasonably well with predicted ranges of approximately 1.75 to 2 and 3.25 to 3.75 at the $10-$ and $100-\mathrm{m}$ AGL levels, respectively. The values at RF are considerably less than at the other sites. The combination of relatively smooth terrain and light winds during unstable conditions allows occasional stalling of the vertical propeller at $\mathrm{RF}$, thereby reducing the mean $\sigma_{w} / u_{*}$ values.

The normalized turbulence parameter profiles show slight changes for the B stability class (Fig. 3). The most important change during B stability is that $\sigma_{v} / u_{*}$ profiles at all fetches converge to between values of 3.0 to 3.6. The $\sigma_{u} / u_{*}$ and $\sigma_{v} / u_{*}$ values for B stability nearly agree, except at RF. The $\sigma_{v} / u_{*}$ continues to decrease slightly with height. The $\sigma_{w} / u_{*}$ profiles show only minor changes from those in A stability.
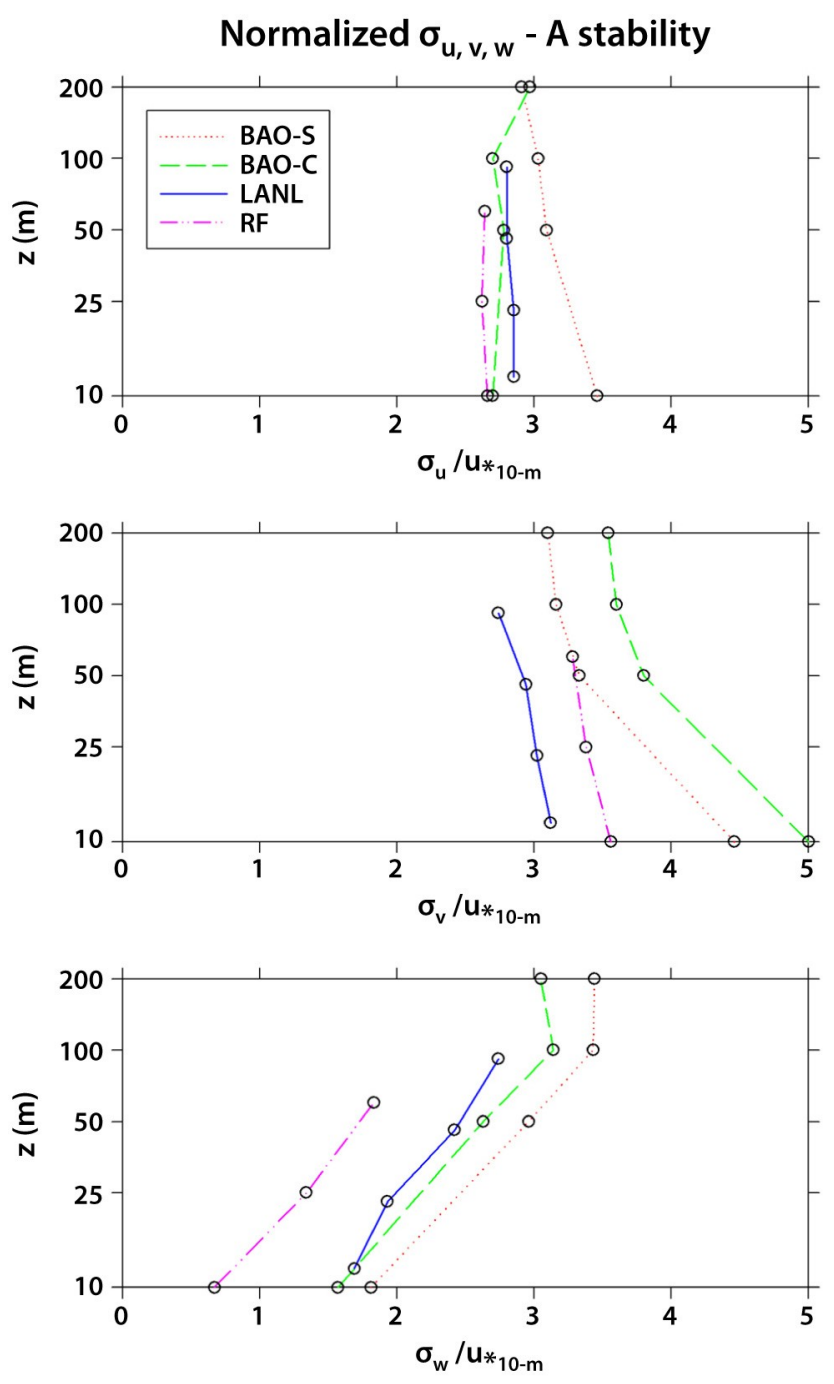

Fig. (2). Normalized turbulence parameter $\left(\sigma_{u, v, w} / u *\right)$ profiles for 4 fetches at 3 sites during A stability.

Normalized turbulence coefficient values decrease as stability approaches neutral (see Fig. 4). Both $\sigma_{u} / u_{*}$ and $\sigma_{v} / u_{*}$ values range from about 2.5 to slightly above 3 for $\mathrm{C}$ stability and are generally constant with height. The $\sigma_{w} / u_{*}$ values have decreased considerably from the transition to $\mathrm{C}$ stability, especially at higher heights. Note that the rate of increase with height of $\sigma_{w} / u_{*}$ has decreased as well. The $\sigma_{w} / u_{*}$ profiles from all 4 fetches now show very good agreement.

The normalized turbulence coefficients decrease further in near-neutral conditions and remain nearly constant with 

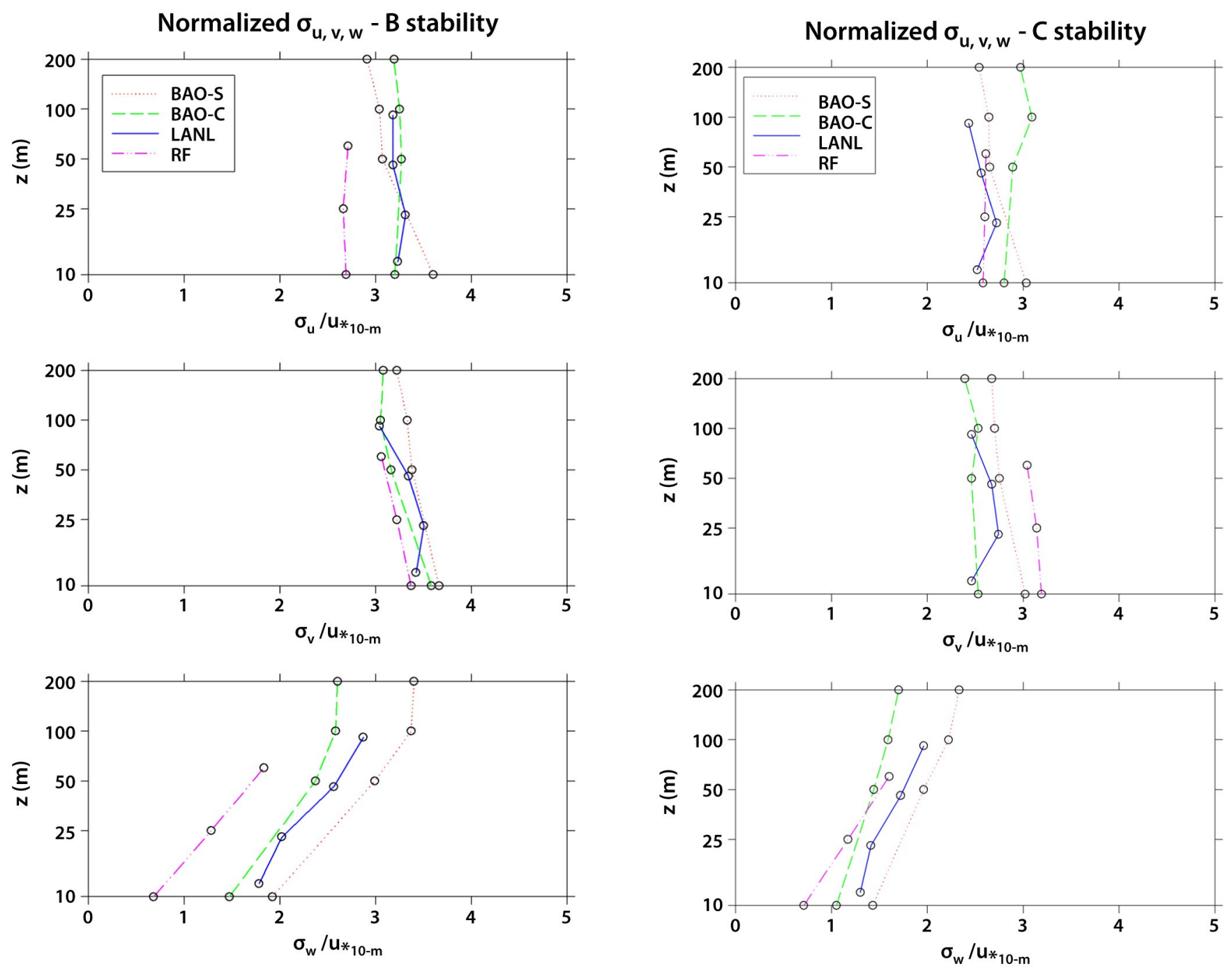

Fig. (3). Same as Fig. (2), except during B stability.

height (see Fig. 5). It is not surprising that lowest-level $\sigma_{u} / u *$ values at all fetches converge closely to the expected value of 2.5, since $z o$ was estimated at all sites assuming the same ratio (the use of Eq. 2). The $\sigma_{v} / u_{*}$ values are only slightly less than $\sigma_{u} / u_{*}$ values, generally equaling or slightly exceeding the widely used ratio of 2 . The median $\sigma_{w} / u_{*}$ values at 10 to $12 \mathrm{~m} \mathrm{AGL}$ are close to one when averaged over all fetches. However, the shapes of the profiles differ according to fetch. The $\sigma_{w} / u_{*}$ profile at BAO with simple fetch indicates little change with height, thereby agreeing with M-O similarity theory. The three $\sigma_{w} / u_{*}$ profiles with complex fetch all indicate an increase with height and therefore depart from similarity theory. Since the number of nearneutral conditions is nearly equal between day and night, and because $\sigma_{w}$ nighttime analyses indicate similar results, it is doubtful that convection skews these results.

The $\sigma_{u} / u_{*}$ and $\sigma_{v} / u_{*}$ profiles for $\mathrm{E}$ stability indicate a slight increase and more variation among fetches compared to D stability (see Fig. 6). Also note that the values are

Fig. (4). Same as Fig. (2), except during C stability.

relatively constant with height. All $\sigma_{w} / u *$ profiles agree remarkably well with each other and indicate an increase with height and departure from similarity theory, regardless of fetch.

The $\sigma_{u} / u_{*}$ and $\sigma_{v} / u_{*}$ values increase to between 3 and 5 during $\mathrm{F}$ stability and show a tendency to increase with height at the lowest levels as shown in Fig. (7). These $\sigma_{w} / u_{*}$ profiles also show a surprising increase with height for all fetch, with an even greater increase with height than for $\mathrm{E}$ stability.

The measured turbulence coefficients exceed widely used values, especially during $\mathrm{F}$ stability. For instance, Hanna et al. [27] suggest near-surface values of 2.0, 1.3, and 1.3 while

Garratt [28] suggests $2.4,1.9$, and 1.25 for $\sigma u, v, w^{/} u_{*}$, respectively. The differences between these measurements and widely used values increases with height, since the previously mentioned and other studies suggest that normalized turbulence coefficients decrease with height and reach small values at the top of the SBL. 

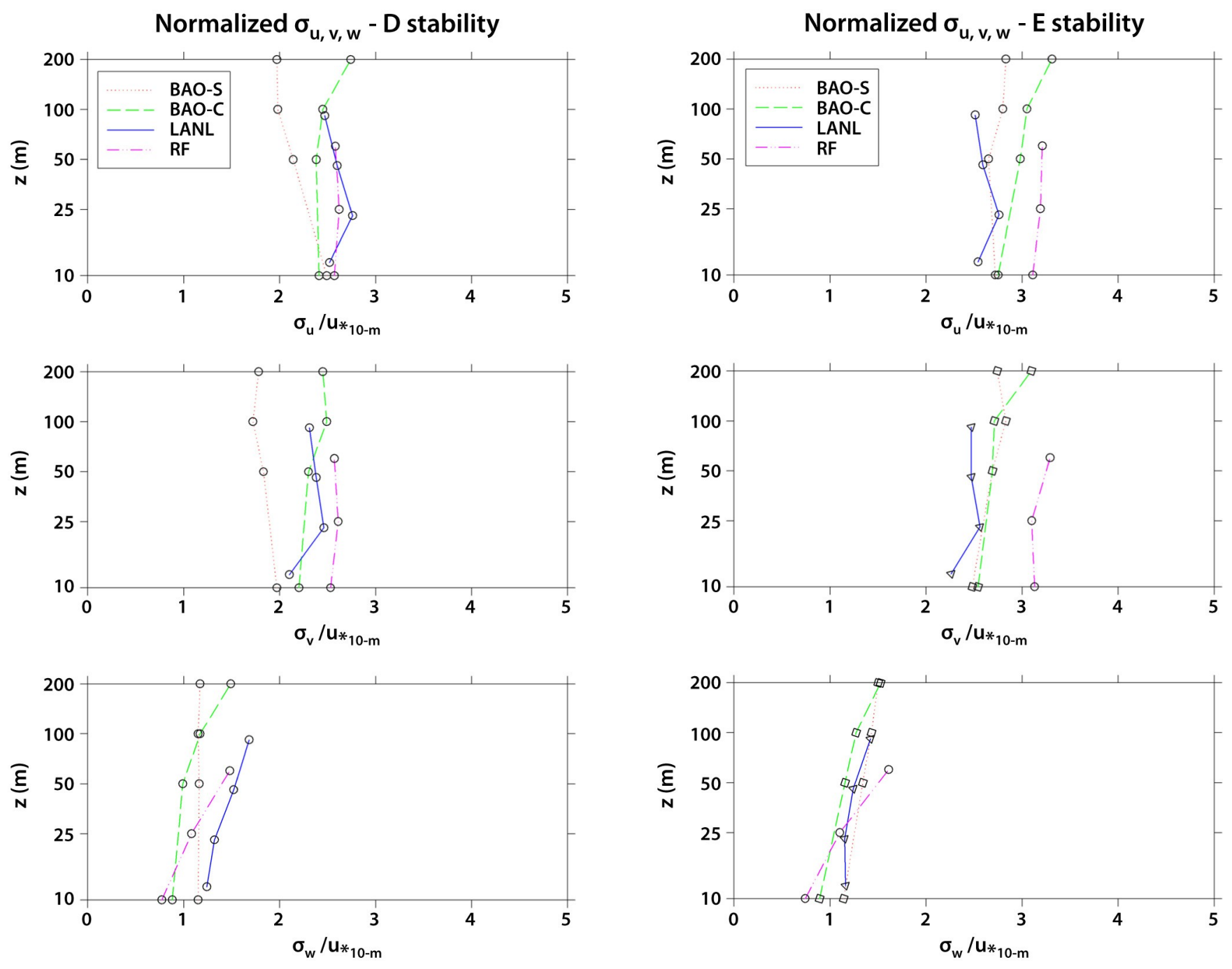

Fig. (5). Same as Fig. (2), except during D stability.

\subsection{Comparison of Predicted with Measured-Derived $\mathbf{u}_{\text {* }}$}

The turbulence coefficient profiles in the previous section were scaled by estimated $u_{*}$ values based on wind speed, stability, and $z_{o}$ because the momentum flux was not measured at the RF tower. Since it is rarely available from routine measurements, the accurate estimation of $u_{*}$ is important because it often is used to calculate vertical diffusivity profiles in advanced dispersion models or estimate turbulence parameters in simpler models. Therefore, medians of all 15minute averaged predicted versus measurement-derived $u$ * $\left(\sqrt{-\overline{u^{\prime} w^{\prime}}}\right)$ were calculated for both the simple and complex fetch at BAO and at the LANL for the 6 stability categories and are plotted in Fig. (8).

Results indicate a very good correlation between predicted and measured $u_{*}$ values, with most differences less than $20 \%$. Large departures of predicted median values $(\sim$ $40 \%$ ) from measured median values occurred for only two situations: A stability for rough fetch at LANL and D stability for complex fetch at BAO. While the median values show

Fig. (6). Same as Fig. (2), except during E stability.

good agreement, there is considerable scatter for individual 15 -minute averages. Note that measured median $u *$ reaches a minimum of about $0.1 \mathrm{~ms}^{-1}$ for all fetch during $\mathrm{F}$ stability but it reaches a much higher maximum of $0.5 \mathrm{~ms}^{-1}$ during $\mathrm{C}$ and D stability at LANL, with its larger $z_{o}$ because of trees, compared to BAO.

\subsection{Angular Wind Direction Fluctuation Standard De- viation Profiles}

The standard deviation of angular wind direction fluctuations in the horizontal $\left(\sigma_{\theta}\right)$ and vertical $\left(\sigma_{\phi}\right)$ are good indicators of atmospheric dispersive capability and they are often used to determine the dispersion parameters $\sigma_{y}$ and $\sigma_{z}$ in simple Gaussian models, or they can be used to calculate $K_{y}$ and $K_{z}$ in more sophisticated models. Profiles of $\sigma_{\theta}$ and $\sigma_{\phi}$ for all stabilities were calculated for each fetch and are shown in Figs. $(\mathbf{9}, \mathbf{1 0})$.

The general reduction of $\sigma_{\theta}$ values as stability increases from A to D stability is similar among all of the fetches. 

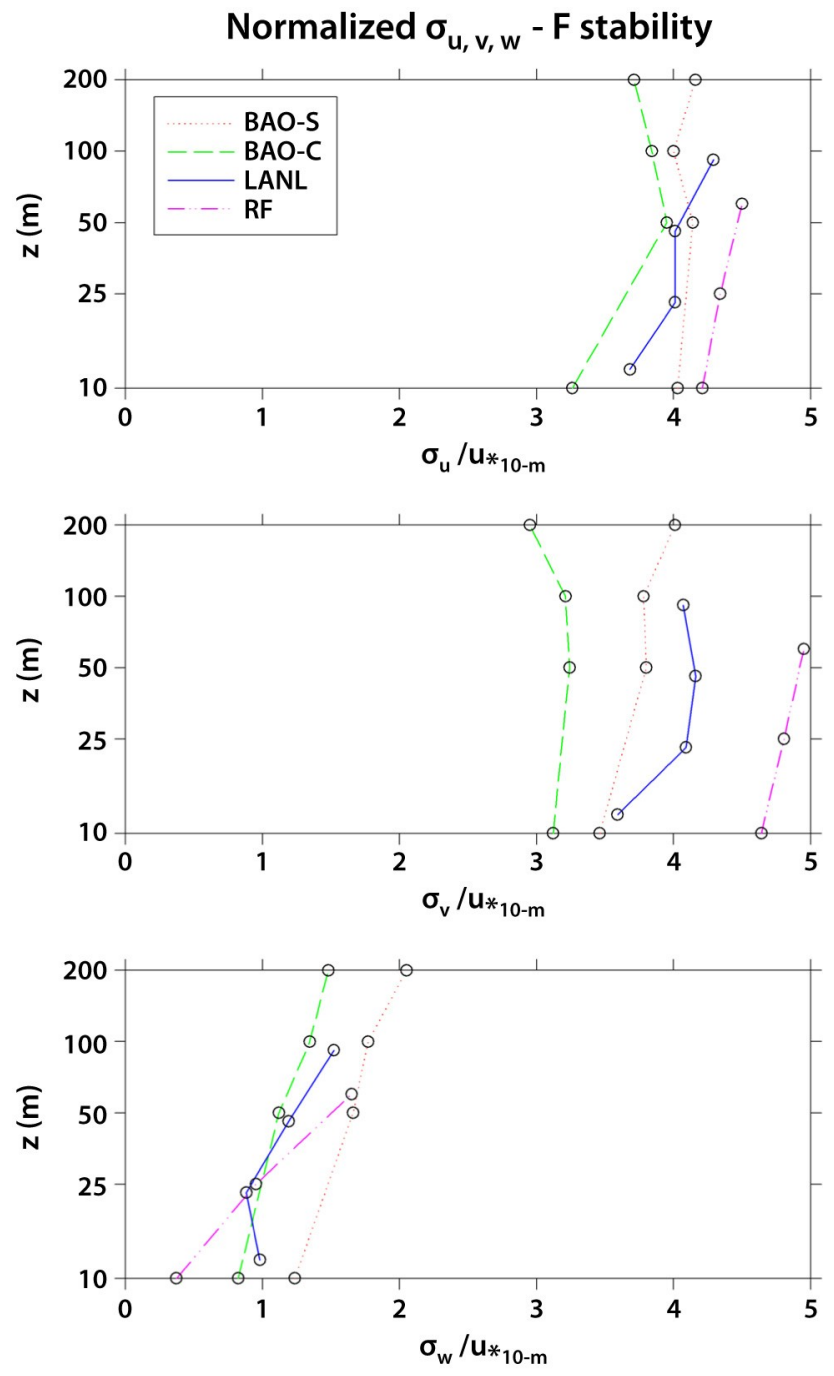

Fig. (7). Same as Fig. (2), except during F stability.

Both the actual values and rate of decrease of $\sigma_{\theta}$ with height compare reasonably well with widely suggested values [1]. However, median $\sigma_{\theta}$ values generally increase at several tower levels for all fetch as conditions become stable. This is especially true at BAO for both simple and complex fetch, where $\sigma_{\theta}$ increases slightly for E stability and then significantly for F stability compared to D stability. The RF site also shows a significant increase in $\sigma_{\theta}$ for $\mathrm{F}$ stability but it shows a very slight incremental decrease from $\mathrm{D}$ to $\mathrm{E}$ stability. The LANL site shows only a significant increase in $\sigma_{\theta}$ at the two upper levels during F stability.

The $\sigma_{\phi}$ profiles also follow expected trends during unstable conditions: the rate of increase with height decreases noticeably as stability increases from A to C stability. Note that the LANL site with nearby trees indicates the largest $\sigma_{\phi}$ values at lowest heights. However, the $\sigma_{\phi}$ values show an increase with height during D stability for both the complex $\mathrm{BAO}$ and RF fetches instead of an expected decrease (i.e., surface layer similarity and log-law theories assume constant $\sigma_{v}$ and an increase of wind speed with height). The increase of $\sigma_{\phi}$ with height does not occur at LANL possibly because the nearby trees generate so much turbulence at the lowest heights.

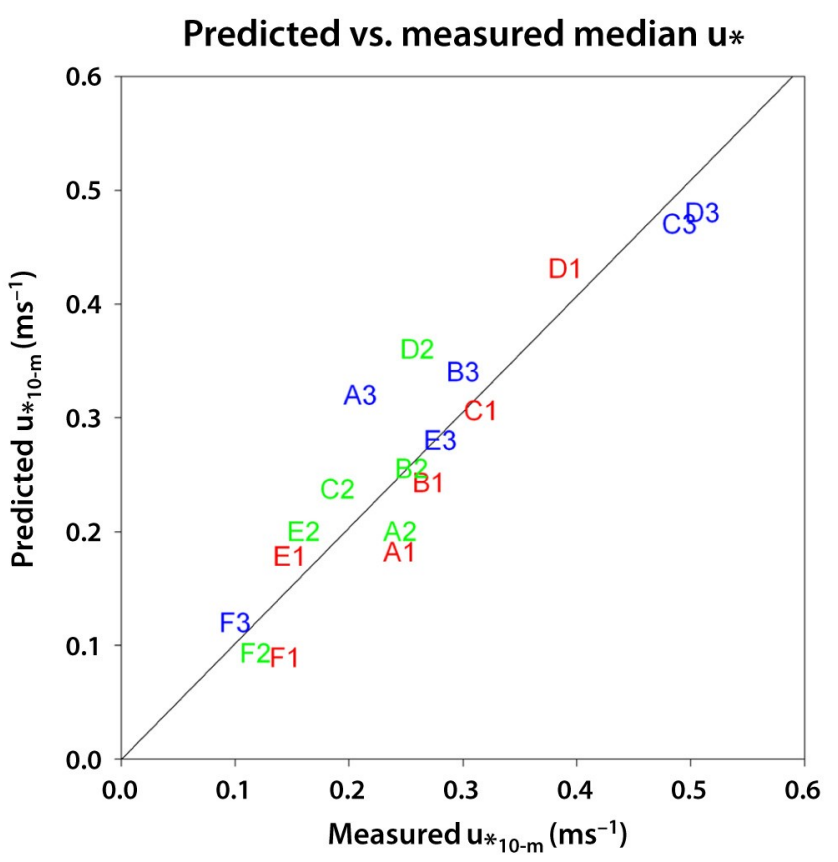

Fig. (8). Scatterplot of medians of 15-minute averaged predicted $v s$ measured $u *$ values for 3 fetches at 2 sites for 6 stability categories. Symbols denote stability category (A, B, C, etc. ) and fetch ( $1=\mathrm{BAO}$ with simple fetch, $2=\mathrm{BAO}$ with complex fetch, $3=\mathrm{LANL})$.

The deviation from similarity theory becomes even more noticeable during stable conditions, as $\sigma_{\phi}$ is relatively constant or it actually increases with height for all fetches. This occurs in spite of the fact that wind speed increases with height for all fetches.

\subsection{F Stability Turbulence Coefficient Profiles}

The interesting behavior of turbulence during the most stable (F) conditions is further examined by observing the non-normalized turbulence coefficient profiles for only $\mathrm{F}$ stability in Fig. (11). Note that the ranges of the median, 10 to $12-\mathrm{m}$ level $\sigma_{u}$ and $\sigma_{v}$ values are very close to the suggested minimum hourly value for $\sigma_{v}$ of $0.5 \mathrm{~ms}^{-1}$ suggested by Hanna and Chang [11] and others. Since hourly values are expected to be approximately $30 \%$ greater than 15 minute averages, these results are consistent with a minimum hourly value of $0.5 \mathrm{~ms}^{-1}$. A somewhat surprising result is that $\sigma_{u}$ and $\sigma_{v}$ values have a tendency to remain constant or increase with height for all fetch. Finally, the assumption that $\sigma_{u}$ and $\sigma_{v}$ values are generally similar to each other in the lowest 100 to $200 \mathrm{~m}$ of the SBL also is reasonable.

The $\sigma_{w}$ profiles show a dramatic departure from M-O similarity theory, increasing rather than decreasing with 
$\sigma_{\theta}$ Profiles by Fetch and Stability
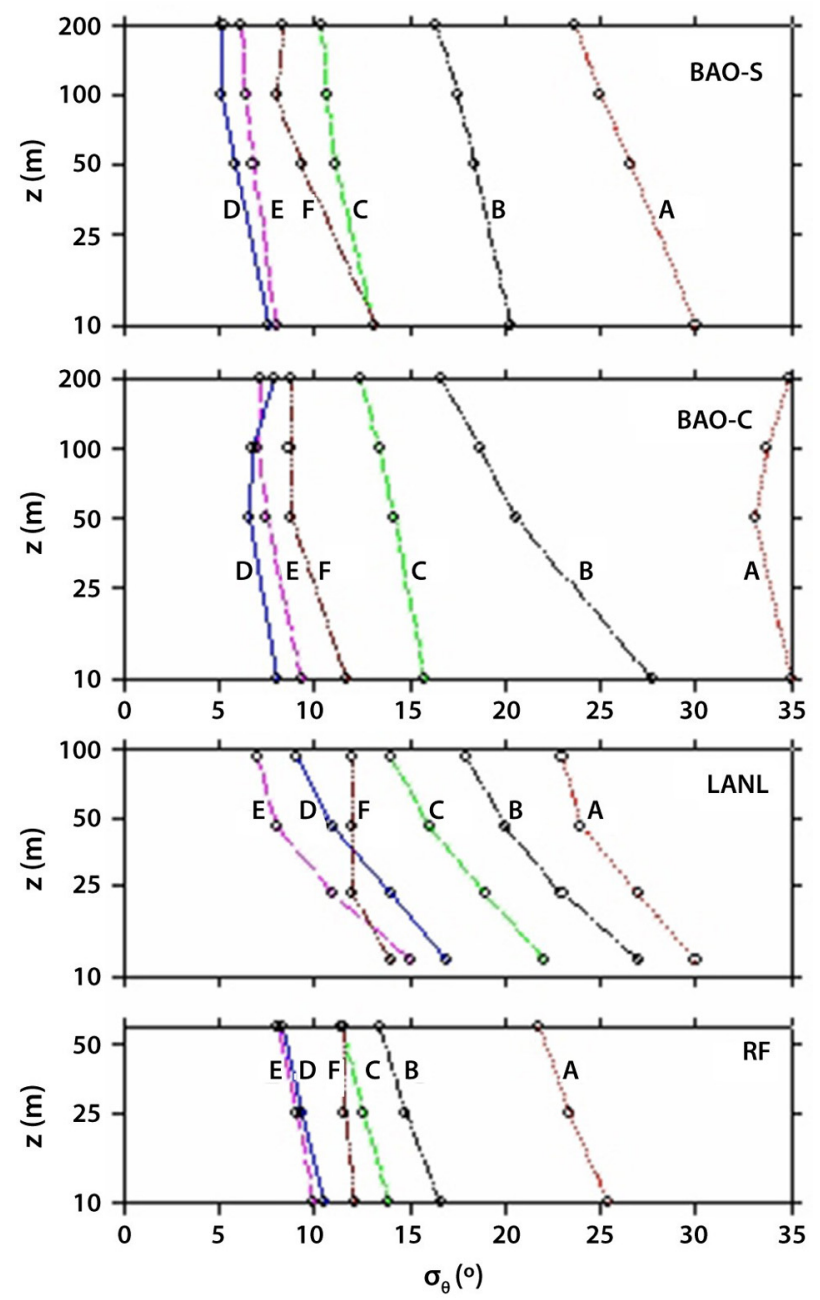

Fig. (9). Measured median $\sigma_{\theta}$ profiles by fetch and stability.

height for all fetch. A composite of all fetches and available heights indicates that $\sigma_{w}$ increases from approximately 0.1 to $0.2 \mathrm{~ms}^{-1}$ between 10 and $200 \mathrm{~m} \mathrm{AGL}$. The long-term increase of median $\sigma_{w}$ values for all fetch implies that much of the vertical turbulent energy typically is generated from above as well as from the ground during very stable conditions. Indeed, the increase of $\sigma_{w}$ with height may be explained by the generation of intermittent turbulence in the upper part of the NBL not directly related to the surface stress [29]. Nappo [30] suggests that this intermittent turbulence can propagate downward in the form of turbulent bursts.

\subsection{Implications for Atmospheric Modeling in SBL}

The effect of enhanced vertical turbulence on diffusion in the SBL can be visualized by examining profiles of estimated $K z$, an important input to some transport and dispersion models. Similarity theory is widely used to calculate $K z$ throughout the surface layer by first estimating $u_{*}$ and $\mathrm{L}$ and using a relationship such as the following suggested by Lange [31]:

$K z=\left[0.4 u * z / \phi_{h}(z / L)\right] e^{-4 z / h}$, where $\phi_{h}$, the dimensionless wind gradient, can be estimated from values suggested by Businger et al. [32], for instance.

\section{$\sigma_{\phi}$ Profiles by Fetch and Stability}
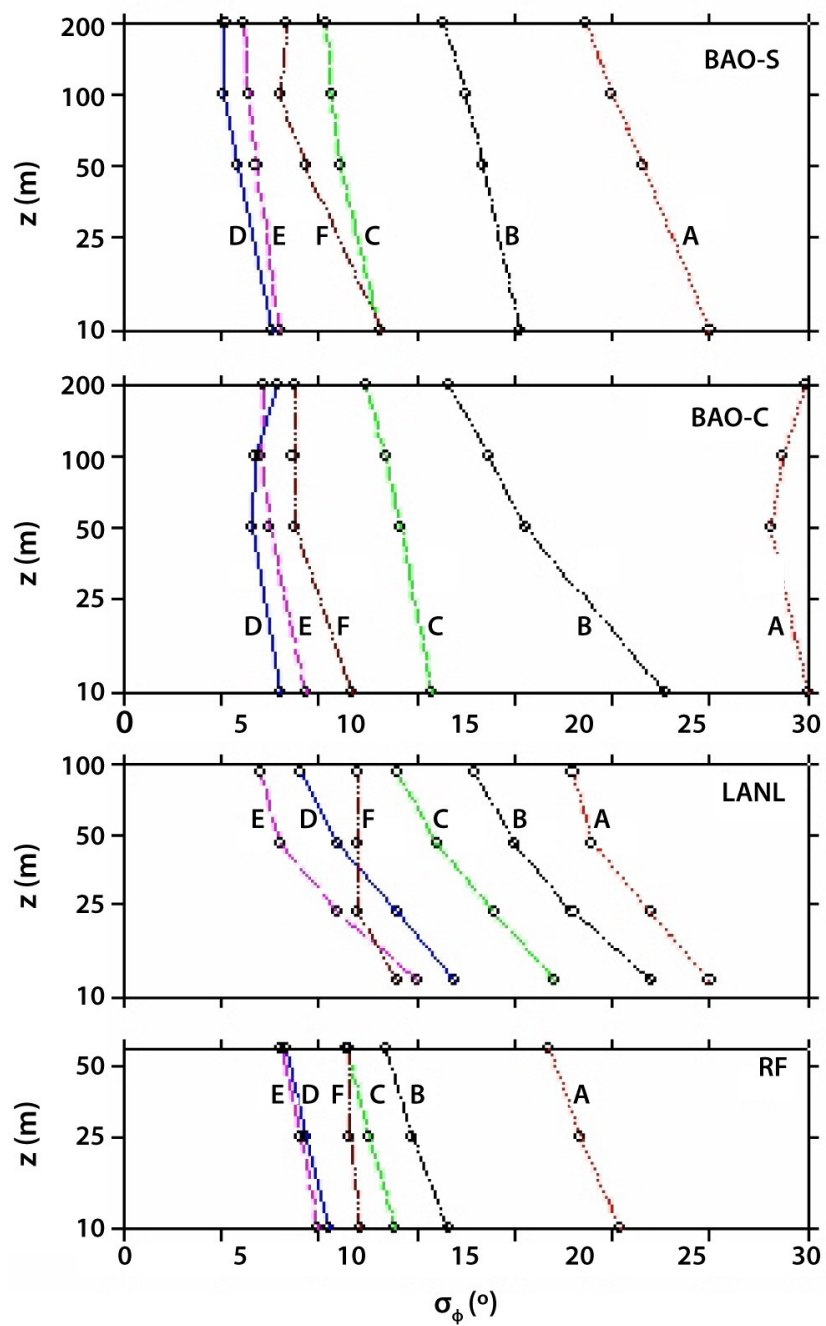

Fig. (10). Measured median $\sigma_{\phi}$ profiles by fetch and stability.

When $\sigma_{w}$ measurements are available, $K z$ can also be calculated from a relationship recommended by Hanna [33]:

$K z=A \sigma_{w} \lambda_{m w}$,

where Pasquill [7] suggests a value of 0.15 for the constant A and $\lambda_{m w}$ is the wavelength at which the vertical velocity turbulent kinetic energy peaks. Kaimal and Finnigan [34] suggest the following relationships to estimate $\lambda m w$ during stable conditions:

$\lambda_{m w}=z(0.55+z / L)^{-1}, 0 \leq z \leq L$

$\lambda_{m w}=z L(0.45 z+1.1 L)^{-1}, L \leq \mathrm{z} \leq 2 \mathrm{~L}$

$\lambda_{m w}=L, z \geq 2 L$.

Profiles of $K z$ were calculated at the BAO tower for all fetch using similarity theory (Eq. 5) and measured $\sigma_{w}$ (Eq. 6) and are shown in Fig. (12) and Table 2. Note that the value of $u *\left(0.1 \mathrm{~ms}^{-1}\right)$ used in Eq. 5 is approximately equal to 
the measured median value. A typical value of $\mathrm{h}(500 \mathrm{~m})$ at BAO is estimated from Holzworth [35]. The 25-and 75percentiles of $\sigma_{w}$-derived $K z$ values incorporate the variations from only $\sigma_{w}$ since $\lambda_{m w}$ is always specified by Eqs. 79. Note the dramatic departure between the two methods to calculate $K z$ : similarity theory in this case indicates a maximum value at about $20 \mathrm{~m}$ while the $\sigma_{w}$ method indicates a sharp increase up to about $50 \mathrm{~m}$ AGL with less increase above. The $\sigma_{w}$ method results in $\mathrm{Kz}$ values 1.5 to 16 times larger than those using similarity theory at $10-$ and $200-\mathrm{m}$ heights (see Table 2), respectively. The variation about the median of $\sigma_{w}$-derived $\mathrm{Kz}$ (Fig. 12) indicates skewness toward larger values.
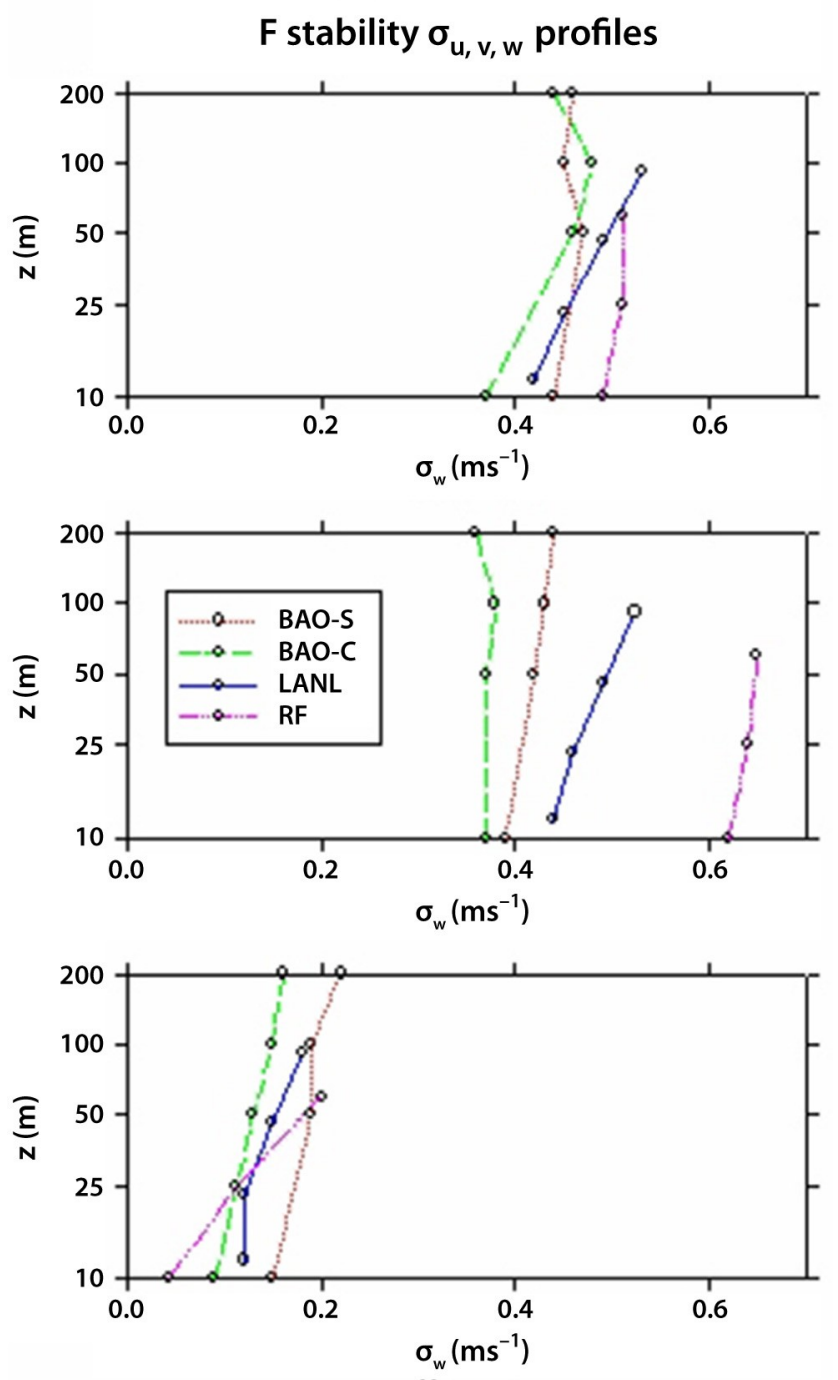

Fig. (11). Turbulence parameter $\left(\sigma_{u, v, w}\right)$ profiles for 4 fetches at 3 sites during $\mathrm{F}$ stability.

The measured $\sigma_{w}$ (and estimated $\mathrm{Kz}$ ) profiles strongly suggest that atmospheric dispersion models that use similarity theory-derived vertical turbulence or diffusivity values may routinely underestimate dispersion in the lowest several hundreds of meters above the ground during very stable conditions, especially farther above the ground. These findings indicate that ground-level atmospheric concentrations resulting from near ground-level releases will typically be lower than what traditional, similarity-based models indicate. More important, the assumption of similarity theory for slightly elevated releases can potentially cause critical modeling errors, whereby the diffusion of hazardous material to the ground is either underestimated or completely missed. Indeed, a unique dual-tracer field study that took place over a flat, suburban area in Norway illustrates how unexpectedly large turbulence in the SBL can cause large modeling errors during very stable conditions [36]. During weak wind $(<1$ $\mathrm{ms}^{-1}$ ) occurrences, the use of surface layer theory (wind and temperature profiles) results in ground level concentrations on the order of 5 times greater than measured and predicted concentrations based on turbulence observations up to $500 \mathrm{~m}$ downwind of a 1-m AGL release. The use of surface layer theory is similarly inadequate in describing vertical diffusion from the elevated 36-m AGL release: measured and modeled concentrations using turbulence measurements indicate that the plume impacts the ground as close as $100 \mathrm{~m}$ downwind. However, the model using surface layer theory shows no ground level concentrations in the first kilometer downwind!

\section{$\mathrm{K}_{\mathrm{z}}$ Estimates during Stable Conditions $\left(\mathrm{h}=500 \mathrm{~m}, \mathrm{~L}=20, \mathrm{u}_{*}=0.1 \mathrm{~ms}^{-1}\right)$}

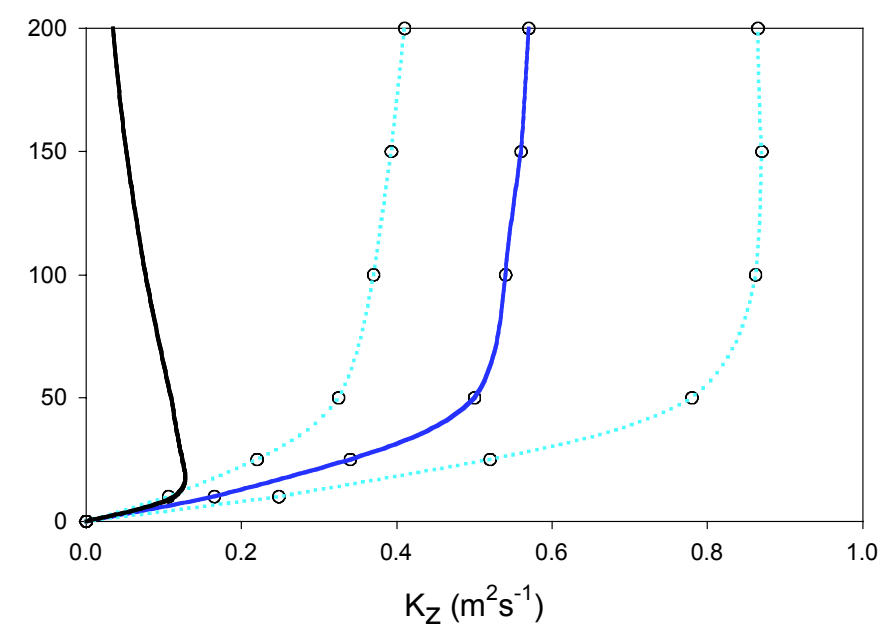

Fig. (12). Estimated median, composite $\mathrm{Kz}$ profiles $\left(\mathrm{m}^{2} \mathrm{~s}^{-1}\right)$ at BAO tower during F stability based on measured $\sigma_{w}$ (blue) and similarity theory (black). Dashed blue lines indicate 25- and 75-percentile values based on $\sigma_{w}$.

Table 2. Estimated Median, Composite Kz Profiles $\left(\mathrm{m}^{2} \mathrm{~s}^{-1}\right)$ at BAO Tower During F Stability Based on Measured $\sigma_{w}$ and Similarity Theory. The Numbers in Parenthesis Represent Variation (25- and 75-Percentile Values) About Median. Assumptions Include Fixed Values of h $(500 \mathrm{~m}), \mathrm{L}(20 \mathrm{~m})$, and $u *\left(0.1 \mathrm{~ms}^{-1}\right)$

\begin{tabular}{|c|c|c|c|}
\hline $\mathbf{z}(\mathbf{m})$ & $\mathbf{K z}\left(\sigma_{w}\right)$ & $\mathbf{K z}$ (Similarity) & Ratio \\
\hline \hline 200 & $\mathbf{0 . 5 7}(-0.16 /+0.30)$ & 0.035 & 16.3 \\
\hline 100 & $\mathbf{0 . 5 4}(-0.17 /+0.32)$ & 0.08 & 7.1 \\
\hline 50 & $\mathbf{0 . 5 0}(-0.18 /+0.28)$ & 0.11 & 4.6 \\
\hline 10 & $\mathbf{0 . 1 6 5}(-0.06 /+0.08)$ & 0.115 & 1.45 \\
\hline
\end{tabular}




\section{CONCLUSIONS AND RECOMMENDATIONS}

Measured long term wind and turbulence parameter profiles up to $200 \mathrm{~m} \mathrm{AGL}$ and $u *$ are analyzed in this study for all stability conditions at three, multi-level towers located in the western U.S. Results show that $\sigma_{u} / u_{*}, \sigma_{v} / u *$, and $\sigma_{w} / u_{*}$ values and profiles for various fetches agree reasonably well with widely used empirical relationships for slightly to strongly unstable conditions, except that $\sigma_{v}$ equals or slightly exceeds $\sigma_{u}$. The normalized horizontal coefficients for all fetches also generally agree with the widely used empirical relationships during near-neutral stability. However, $\sigma_{w}$ profiles depart from these relationships and similarity theory for three more complex fetches during near-neutral stability as $\sigma_{w}$ increases approximately 50 to $100 \%$ in the lowest 60 to $200 \mathrm{~m}$. The $\sigma_{w}$ values remain nearly constant in the lowest $200 \mathrm{~m}$ with simple fetch. The $\sigma_{w} / u *$ values equal approximately one at the 10-m height for both simple and complex fetch. Values of $\sigma_{u}$ and $\sigma_{v}$ are nearly constant with height for all fetches. The $\sigma_{u} / u *$ and $\sigma_{v} / u *$ values remain relatively constant with height but they increase slightly for slightly stable and then increase to between 3 and 5 for very stable conditions. The $\sigma_{w} / u *$ values show a surprising increase of approximately 50 to $100 \%$ in the lowest 100 to $200 \mathrm{~m}$ during $\mathrm{E}$ and $\mathrm{F}$ stability for all fetch, respectively. The $10-\mathrm{m} \sigma_{w} / u *$ values approximately equal one for stable conditions for all fetch. A comparison of predicted and measured $u *$ values at two of the sites show generally good agreement over 6 stability ranges. Finally, measured $\sigma_{w}$ at two of the sites suggest that M-O similarity theory routinely greatly underestimates vertical diffusivity and dispersion during very stable conditions, especially at larger heights, which could thereby lead to large errors in simulated surface concentrations.

Since vertical turbulence is typically not measured routinely on tall towers, and because current ground-based remote sensors are incapable of providing reliable turbulence profiles [37], there is not a large sample with experimental or routine measurements with accurate, deep turbulence profiles. Even though Crescenti [37] indicates that sodar-derived $\sigma_{w}$ values show much promise, vertical sodar profiles are often limited in height during neutral and stable conditions.

Based on findings from this study of measurements from tall towers over the western U.S., the following rules of thumb are suggested to describe departure from similarity theory during breezy, near-neutral and stable conditions:

1. For areas in complex terrain or areas up to at least 5 to $10 \mathrm{~km}$ or so downwind of sharp terrain rises or dips of 15 to $25 \mathrm{~m}$ or so, $\sigma_{w} / u *$ increases by about 50 to $100 \%$ in the lowest 60 to $200 \mathrm{~m}$ from its approximate value of one at $10 \mathrm{~m} \mathrm{AGL}$. Both $\sigma_{u} / u *$ and $\sigma_{v} / u *$ increase with height only slightly and range between 2.5 to 3.5 ;

2. During stable conditions, $\sigma_{u} / u *$ and $\sigma_{v} / u *$ increase slightly to about 3 during E stability and to between 3 and 5 during $\mathrm{F}$ stability, with a tendency to increase slightly with height. The $\sigma_{w} / u *$ values typically increase from approximately one at the $10-\mathrm{m}$ level to about 1.5 and nearly 2 at $200 \mathrm{~m}$ AGL for E and F stability, respectively.

3. During F stability, $\sigma_{u}$ typically varies between 0.4 to $0.5 \mathrm{~ms}^{-1}$ and $\sigma_{v}$ typically varies between 0.4 and 0.6 $\mathrm{ms}^{-1}$ in the lowest $200 \mathrm{~m}$, with both variables showing a slight tendency to increase with height. The $\sigma_{w}$ typically increases from 0.1 to $0.2 \mathrm{~ms}^{-1}$ between the 10- and 200-m levels.

4. Since $\sigma_{w}$ typically increases in the lowest $200 \mathrm{~m}, \mathrm{Kz}$ estimated from $\sigma_{w}$ is 1.5 to 16 times the value than when similarity theory is assumed. Therefore the use of similarity theory in very stable conditions (e.g., F stability, $\mathrm{L}>0.2$ to 0.4 , etc.) in atmospheric dispersion models may cause much too little vertical diffusion in the lowest $200 \mathrm{~m}$ or so. This is turn will result in overestimation of near-surface releases and more importantly, often significant underestimation of slightly elevated releases.

\section{ACKNOWLEDGEMENTS}

I thank the following persons for supplying the data used in this study: Brian Templeman of CIRES, University of Colorado (BAO); Darrell Holt of LANL; and Carey Dickerman of FNMOC, Monterrey, CA (formerly at Rocky Flats Environmental Plant). I appreciate John Nasstrom, Ph.D., of Lawrence Livermore National Laboratory for reviewing this manuscript and making helpful comments. This work was performed under the auspices of the U.S. Department of Energy by the Lawrence Livermore National Laboratory under contract No. W-7405-Eng-48.

\section{REFERENCES}

[1] EPA (U.S. Environmental Protection Agency), Meteorological monitoring guidance for regulatory modeling applications. EPA454/R-99-005, Office of Air Quality Planning and Standards, Research Triangle Park, NC; 2000.

[2] Hicks BB. Monin-Obukhov similarity-An historical perspective. Eleventh Symposium on Boundary Layers and Turbulence, Charlotte, NC. Am Meteor Soc 1995; 1-4.

[3] Panofsky HA, Egolf CA, Lipschutz R. On characteristics of wind direction fluctuations in the surface layer. Bound Layer Met 1978; 15: 439-46.

[4] Hanna SR. Measured $\sigma_{y}$ and $\sigma_{\theta}$ in complex terrain near the TVA Widows Creek. Alabama Steam Plant. Atmos Environ 1980; 14: 401-7.

[5] Ludwig FL, Dabberdt WF. Comparison of two practical atmospheric stability classification schemes in an urban atmosphere. J Appl Meteor 1976; 15: 1172-6.

[6] Tieleman HW. Wind characteristics in the surface layer over heterogeneous terrain. J Wind Eng Ind Aerodyn 1992; 1: 329-40.

[7] Pasquill F. Atmospheric Diffusion, 2nd Ed. John Wiley and Sons, 1974; 429 pp. (see page 77).

[8] Beljaars ACM, Schotanus P, Nieuwstadt FTM. Surface layer similarity under nonuniform fetch conditions. J Clim Appl Meteor 1983; 22: 800-1810.

[9] Bowen BM. Neutral surface layer turbulence over complex terrain. Ninth Joint Conf. on the Applications of Air Pollution Meteorology, Atlanta, GA. Am Meteor Soc 1996; 411-416.

[10] Bowen BM. Near-neutral surface layer turbulence at the Boulder atmospheric observatory tower. J Appl Meteor 2000; 39: 716-24. 
[11] Hanna SR, Chang JC. Boundary-layer parameterizations for applied dispersion modeling over urban areas. Bound Layer Met 1992; 58: 229-59.

[12] Weber AH, Kurzeja RJ. Nocturnal planetary boundary layer structure and turbulence episodes during the Project STABLE field program. J Appl Meteor 1991; 30: 1117-33.

[13] Banta RM, Olivier LD, Gudiksen PH. Implications of small-scale flow features to modeling dispersion over complex terrain. J Appl Meteor 1995; 35: 330-42.

[14] Schotz S, Panofsky HA. Wind characteristics at the Boulder Atmospheric Observatory. Bound-Layer Met 1980; 17: 333-51.

[15] Crescenti GH. Development of quality assurance and quality control guidance for ground-based remote sensors for use in regulatory modeling. Ninth Joint Conf. on the Applications of Air Pollution Meteorology, Atlanta, GA. Am Meteor Soc 1996; 551-55.

[16] Sedefian L, Bennett E. A comparison of turbulence classification schemes. Atmos Environ 1980; 14: 741-50.

[17] Businger JA. Turbulent transfer in the atmospheric surface layer. Workshop on Micrometeorology. Amer Meteor Soc 1973; pp. 67120.

[18] Holtslag AAM, Van Ulden AP. A simple scheme for daytime estimates of the surface fluxes from routine weather data. J Clim Appl Meteor 1983; 22: 517-29.

[19] Dyer AJ. A review of flux-profile relationships. Bound-Layer Met 1974; 7: 363-72.

[20] Paulson CA. The mathematical representation of wind speed and temperature profiles in the unstable atmospheric surface layer. $\mathrm{J}$ Appl Meteor 1970; 9: 856-61.

[21] Arya SP. Air Pollution Meteorology and Dispersion. Oxford University Press, 1999.310 pp. (see Chapter 4).

[22] Golder D. Relations among stability parameters in the surface layer. Bound Layer Met 1972; 3: 47-58.

[23] Verkaik JW, Holtslag AAM. Wind profiles, momentum fluxes and roughness lengths. Bound Layer Met 2007; 122: 701-19.

[24] Gryning SE, Batchvarova E, Brummer B, Jorgensen H, Larsen S. Bound-Layer Met 1972; 24: 251-68.
[25] Tieleman HW. Stong wind observations in the atmospheric surface layer. J Wind Eng Ind Aerodyn 2008; 96: 41-77.

[26] Panofsky HA, Tennekes H, Lenschow DH, Wyngaard JC. The characteristics of turbulent velocity components in the surface layer under convective conditions. Bound Layer Met 1977; 11: 355-61.

[27] Hanna SR, Briggs GA, Hosker RP. Handbook on atmospheric diffusion. U.S. Dept. of Energy Report DOE/TIC-11223, 102 pp. [Available from NTIS, U.S. Dept. of Commerce, Springfield, VA 21161.] 1982.

[28] Garratt JR. The atmospheric boundary layer. Cambridge University Press, 1992; pp. 316

[29] Mahrt L. Vertical structure and turbulence in the very stable boundary layer. J Atmos Sci 1985; 42: 2333-49.

[30] Nappo CJ. Sporadic breakdowns of stability in the PBL over simple and complex terrain. Bound Layer Met 1991; 54: 69-87.

[31] Lange R. Transferability of a three-dimensional air quality model between two different sites in complex terrain. J Appl Meteor 1989; 28: 665-79.

[32] Businger JA, Wyngaard JC, Izumi Y, Bradley EF. Flux-profile relationships in the atmospheric surface layer. J Atmos Sci 1971; 28: 181-9.

[33] Hanna SR. A method of estimating vertical eddy transport in the planetary boundary layer. J Atmos Sci 1968; 25: 1026.

[34] Kaimal JC, Finnigan JJ. Atmospheric Boundary Layer Flows. Oxford University Press, 1994; pp. 289 (see Chapter 2).

[35] Holzworth GC. Mixing heights, wind speeds, and potential for urban air pollution throughout the contiguous United States. U.S. Environmental Protection Agency Office of Air Programs Publication No. AP-101, 118 pp. [Available from Superintendent of Documents, U.S. Govt. Printing Office, Washington, D.C. 20402] 1972.

[36] Gronskei KE. Variation in dispersion conditions with height over urban areas - results of dual tracer experiments. Preprints, Ninth Symposium on Turbulence and Diffusion, Roskilde, Denmark, Am Meteor Soc 1990; 297-300.

[37] Crescenti GH. A look back on two decades of Doppler sodar comparison studies. Bull Amer Soc 1997; 78: 651-73. 